\title{
Bulk compression characteristics of straw and hay
}

\author{
Kenny Nona ${ }^{\mathrm{a}, 1, *}$, Bart Lenaerts ${ }^{\mathrm{a}}$, Erdal Kayacan ${ }^{\mathrm{a}}$, Wouter Saeys ${ }^{\mathrm{a}}$ \\ ${ }^{a}$ KU Leuven - University of Leuven, Department of Biosystems (BIOSYST), Division of Mechatronics, Biostatistics and Sensors \\ (MeBioS), Kasteelpark Arenberg 30, 3001 Leuven, Belgium
}

\begin{abstract}
Compression of biological materials facilitates their transport and storage. In agriculture, straw and hay are commonly compressed with extrusion, but this process is highly influenced by changing crop conditions. A mathematical description of the compression profile of fibrous materials would be useful to compare the compression characteristics of different materials and to predict the energy required for compressing it to a certain density. In this study, different biomass modelling techniques have been reviewed to select the most useful crop compression model. It is shown that the selected crop model (Faborode model) is appropriate in describing the crop compression up to a density of $145 \mathrm{~kg} \mathrm{~m}^{-3}$, dry matter (with $R^{2}>0.8$ ). The selected stress-deformation relation (Faborode model) involves two crop parameters which are determined for wheat straw and hay at different moisture contents and particle orientations (random and parallel stacking). These parameters allow for separating the time-dependent and the elastic compression behaviour. The relaxation properties of the samples have been estimated by fitting the stress decay over time. It is shown that a Maxwell model cannot properly describe the relaxation $\left(R^{2}>0.7\right)$ while the Peleg model resulted in reasonable fits with high $R^{2}(>0.8)$. Although the model of Peleg is accurate only after a relaxation time of one second, the parameters can be used in describing the relaxation behaviour.
\end{abstract}

Keywords: crop parameter, compression phase, relaxation, particle orientation

\section{Introduction}

Crop residues, such as straw and hay, represent a continuously increasing share of the farmer's income. Agricultural land produces large volumes of these residues but collecting them requires high costs of labour, manpower as well as high transport expenses. Compressing these materials makes them easier to handle and reduces these costs. Since a high density for the material is needed at high capacities, extrusion is preferred over a fixed wall compression. However, due to frictional heating of the compression chamber this process requires more power resulting in a higher fuel consumption.

\footnotetext{
${ }^{*}$ Corresponding author.

Tel.: +32 16321 444; Fax.: +32 16328590

E-mail address: kenny.nona@biw.kuleuven.be

${ }^{1}$ Agency for Innovation by Science and Technology in Flanders (IWT)
}

Minimizing the energy consumption without decreasing the capacity or density is a trade-off between frictional heating and providing clamping force. Therefore, a mathematical description of the stress-deformation relation of the straw is needed but due to the biological variability, the non-linearity of this relation and the effect of external variables such as moisture content and particle size, several different models have been suggested in literature. The effects of moisture content and particle size on the compression profile are respectively described in Galedar et al. (2008) and O'Dogherty \& Gilbertson (1988). To keep the overview of the current state-ofthe-art, not all the different models will be cited, but their approaches are highlighted.

Material compression is modelled with three basic techniques. The first is the dimensional analysis in which all the variables influencing the compression are combined into dimensionless parameters and

January 16, 2014 


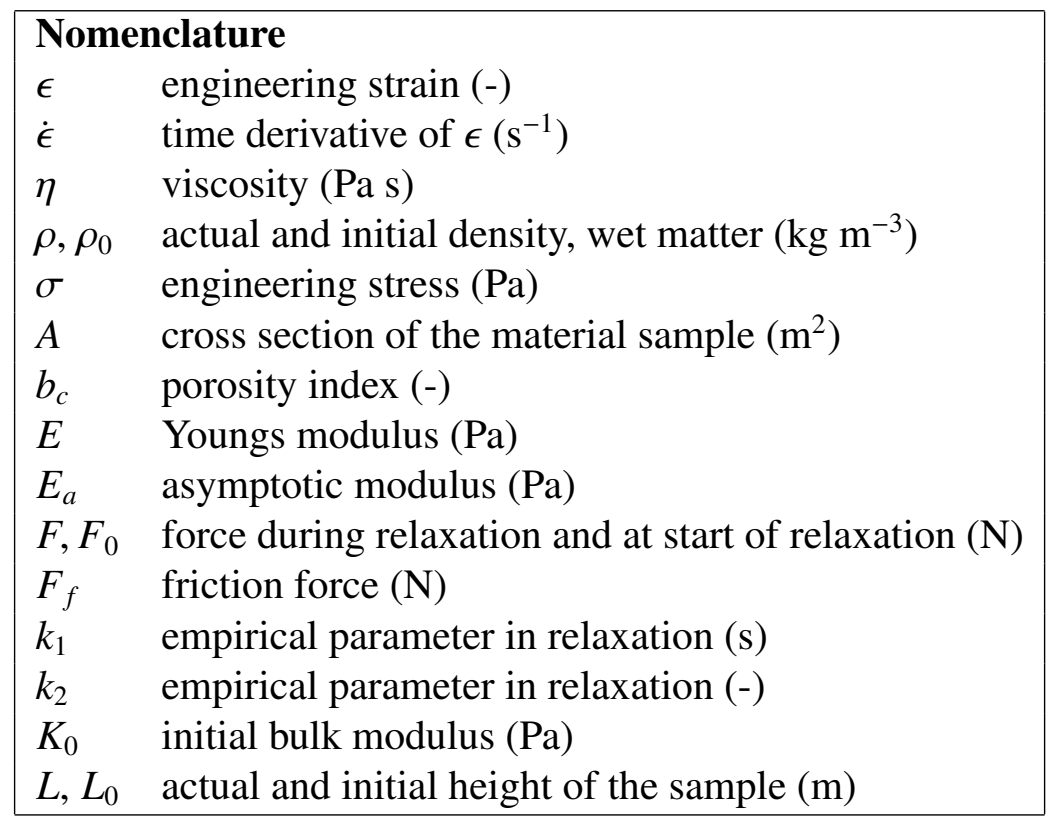

then, by use of the $\pi$-Buckingham theorem, a relation between these parameters is developed. Because dimensional analysis copes with all the variables influencing compression, it produces a so-called general equation (Rehkugler \& Buchele, 1969). The downside is the complexity and the lack of meaningful parameters. In a second approach, simpler equations can be derived empirically by fitting a power-law of pressure to density. Here, the values of the parameters determine their dimensions, thereby reducing their interpretability. Because the stress-deformation ratio increases with deformation, quadratic and exponential relations are also defined. An overview of power-law, exponential and quadratic relations can be found in O' Dogherty (1989), Adapa, Tabil \& Schounau (2009), Viswanathan \& Gothandapani (1999) and O'Dogherty \& Wheeler (1984). In the third technique, the crop models are derived by making some assumptions on the physics of the compression behaviour. Usually, the physics is represented with phases in the compression and the resulting model parameters are better understood than the parameters in other models from literature. However, different authors use different model parameters. Faborode \& O' Callaghan (1986) use the initial bulk modulus and an index related to the material porosity to describe the compression of fibrous agricultural materials. Chen, Cheng \& Chou (2001) on the other hand, expressed the bulk modulus as a function of the initial bulk modulus, the compressibility of the solid, the porosity and an empirical factor. They then used the definition of the bulk modulus to relate the applied compression with the required compression stress. In a more recent publication, Kaliyan \& Vance Morey (2009) use parameters for describing the compression of a mechanical analogy of the biomass. They identified a total of 5 parameters to describe the elastic and plastic deformation, the viscous dissipation and the frictional loss. Similar compression phases therefore have different crop parameters and their mutual relation in the elasto-visco-plastic behaviour is not investigated. Moreover, the material parameters in literature usually describe chopped straw or hay and are usually measured for small masses of samples used for the studies. Because the average length of wheat straw is between $0.60 \mathrm{~m}$ (Annoussamy, Richard, Recous \& Guérif, 2000) and $0.85 \mathrm{~m}$ (Landbouwcentrum Granen Vlaanderen, 2009) and parameters of small crop samples cannot capture the complete bulk characteristics, a new set of parameters has been measured in this study.

\subsection{Modelling of the compression}

Modelling the material compression with the third technique implies an understanding of the mechanism of compression. Hence, interpretable material parameters will be defined. In literature, material compression is divided into several phases 
(Faborode \& O' Callaghan, 1987, 1989; Kaliyan \& Vance Morey, 2009) where each phase is characterised by certain material behaviour. In the first phase, the bulk material has large air voids and the compression largely consists of pushing this air out, resulting in a large plastic deformation. In the next phase, the compression of the particles itself begins and an elasto-visco-plastic compression occurs (Faborode \& O' Callaghan, 1989; Kaliyan \& Vance Morey, 2009).

The assumptions in compression modelling are determined by simplifications in these phases. Doing so, Chen et al. 2001 assumed the relative change in volume to be a linear function of the pressure only. This assumption then results into the definition of the bulk modulus. Another approach is described by Osobov (1967), as cited in Faborode \& O' Callaghan (1986). Here, the change of pressure with density is assumed to only depend on the pressure and this relation is assumed to be linear. Faborode \& O' Callaghan (1986) built on this model by writing the compression pressure as a function of the relative density ratio. They were also able to interpret their model parameters. Faborode \& O' Callaghan (1986) showed the validity of this model until the flexure point in the force-deformation relation. Later, Faborode \& O' Callaghan (1989) defined a third phase for higher densities at which the material acts as a solid. They defined the start of this phase by the point at which the slope of the force-deformation curve is the steepest. Talebi, Tabil, Opoku \& Shaw (2011) showed the applicability of the model of Faborode \& O' Callaghan (1986) to hay for densities up to $500 \mathrm{~kg} \mathrm{~m}^{-3}$ for moisture contents between 7.44 - 18\%wb (405- $463 \mathrm{~kg} \mathrm{~m}^{-3}$, dry matter).

\subsection{Compression curves with time-dependency}

The deformation of agricultural materials depends on both stress and duration of compression (Sitkei, 1986). Therefore, crop parameters will both indicate the instant (elastic) and the time-dependent (viscous) deformation. A rate-dependent compression model can be built by assuming the total deformation to be the sum of the elastic and viscous deformation or by taking the total force as the sum of elastic and viscous forces. These models are respectively the Maxwell and the Kelvin-Voight model and can also be combined in describing more complex elastovisco-plastic behaviour.

The effect of relaxation of biological materials is described with the rate of stress decay at a constant deformation. Peleg (1980) linearised this relaxation curve by considering the relative compression forces with respect to time, but reported that the initial decay rate can depend on the time of straining. Because the decay of stress with time can also be modelled with a Maxwell model, a second relaxation parameter can be determined. In the current study, the proper relaxation model is selected and the parameters are interpreted.

\subsection{Contributions of this study}

Compression of biological materials is very complex and different authors use different models, resulting in several crop parameters. Although the interpretation of these models with their parameters is important in understanding the compression process, many researchers use empirical models where parameters are difficult to interpret. Therefore, assumption-based compression models are preferred but the mutual relation between the parameters describing similar compression phases is usually not investigated. Moreover, existing literature only considers particle sizes which are smaller than the particle sizes of crops that are baled which questions the usage of these parameters in studying the bulk compression characteristics.

Therefore, the objectives of this study are the following:

- investigate the accuracy of the Faborode and Maxwell model in compression modelling and indicate their similarities

- characterise fibrous materials by using crop parameters of the compression and relaxation profile

- contribute to the understanding of crop compression

\section{Material and methods}

\subsection{Compression modelling}

The constitutive relation of a biological material has both an elastic and a plastic component. A 
simple representation is also given by the Maxwell model which assumes a superposition in deformation $\epsilon$ :

$$
\epsilon=\epsilon_{\text {elastic }}+\epsilon_{\text {viscous }}
$$

Assuming Hookean elastic stress $\left(\sigma=E \epsilon_{\text {elastic }}\right)$ and Newtonian viscosity $\left(\sigma=\eta \dot{\epsilon}_{\text {viscous }}\right)$, the following formula can be derived:

$$
\dot{\epsilon}=\frac{\dot{\sigma}}{E}+\frac{\sigma}{\eta}
$$

Equation 2 is solved for $\sigma(t)$ for a constant relative loading rate of $\dot{\epsilon}=R$ (Mohsenin, 1986; Sitkei, 1986):

$$
\sigma=-R \eta\left(e^{-\frac{E}{\eta} t}-1\right)
$$

where $\eta \cdot E^{-1}$ is the relaxation time. By considering $\epsilon=\dot{\epsilon} t=R t$, this equation can be re-written as (Mohsenin, 1986, p.169):

$$
\sigma(\epsilon)=-R \eta\left(e^{-\frac{E}{R \eta} \epsilon}-1\right)
$$

Faborode (1986) also described the compression behaviour of fibrous agricultural materials. This model assumes a linearly increasing slope of stress with density with a uniform variation of the lateral pressure and a constant compression rate $(R)$. The Faborode model relates the compression pressure $P$ with the density $\rho$ as:

$$
P=\frac{K_{0}}{b_{c}}\left(e^{b_{c}\left(\rho / \rho_{0}-1\right)}-1\right)
$$

where $\rho_{0}$ is the initial material density, $K_{0}$ is the initial bulk modulus and $b_{c}$ is the porosity index which is related to the porosity of the material.

The similarity between the Maxwell (Eq. 4) and Faborode (Eq. 5) models can be seen by comparing their definition of deformation. Because of a constant cross-section and mass during the compression, and with the definition of the engineering strain $\left(\epsilon \triangleq\left(L-L_{0}\right) \cdot\left(L_{0}\right)^{-1}\right)$, it follows that:

$$
\frac{\rho}{\rho_{0}}-1=\frac{L_{0}-L}{L}=\frac{-\epsilon}{1+\epsilon}
$$

For small deformation $(\epsilon<<1)$, the term $\left(\rho \cdot \rho_{0}^{-1}-1\right)$ in Eq. 5 reduces to $-\epsilon$. By taking $b_{c}^{\prime}=E \cdot(R \eta)^{-1}$ and $K_{0}^{\prime}=E$, Eq. 4 is equal to Eq. 5 , for small deformations. It has to be noted that due to the definition of the relative deformation, the sign of the compression force is positive in the Faborode model and negative in the Maxwell model, which should be taken into account.

The similarity between the Maxwell and Faborode model allows a better comprehension of their parameters. Indeed, the separation of the elastic and viscous strain in the Maxwell model also separates the elastic and viscous behaviour of the parameters in the Faborode model. In the Maxwell model, Mohsenin (1986) identified $E$ as the initial slope of the compression curve. Faborode \& O' Callaghan (1986) confirm this by describing $K_{0}$ as the initial resistance to compression and showed its increase with the initial density. In this initial compression phase, $E$ is independent of $R$ (Mohsenin, 1986). On the other hand, $b_{c}$ represents the visco-plastic component and determines the increase of stress at the higher compressed densities. In this phase, Mohsenin (1986) indicated the dependency of the stress-deformation on both $E$ and $R$, as indicated by the similarity.

\subsection{Relaxation modelling}

The Maxwell model describes the plasticity during loading (Eq. 4) but can also describe the stress decay with time (Eq. 2 with $\dot{\epsilon}=0$ ):

$$
\sigma=\sigma_{0} e^{-(E / \eta) t}
$$

with $\sigma(t=0)=\sigma_{0}$ the stress at start of relaxation. In this model, the relaxation time $\eta \cdot E^{-1}$ describes the time until the stress has decayed to $e^{-1}$ (approximately $36.8 \%$ ) of its initial value (Sitkei, 1986).

A second relaxation model is given by Peleg (1980) as:

$$
\frac{F_{0} t}{F_{0}-F(t)}=k_{1}+k_{2} t
$$

where $F_{0}$ is the force at the beginning of the relaxation, $t$ is the time, and $k_{1}$, and $k_{2}$ are empirical parameters. It is to be noted that $k_{1}^{-1}$ is the initial decay rate of the force $F$ with time and $k_{2}^{-1}$ is the decay rate of the relative force $\left(F_{0}-F(t)\right) \cdot F_{0}^{-1}$ near the end of relaxation. The model of Peleg is used to define the asymptotic modulus $E_{a}$ as (Peleg, 1980):

$$
E_{a}=\frac{F_{0}\left(1-1 / k_{2}\right)}{A \epsilon}
$$


where $A$ is the cross sectional area of the sample and $\epsilon$ is the applied relative deformation. The asymptotic modulus is a measure for the power of the material to resist the applied stress (Peleg, 1980). Talebi et al. 2011 used the $E_{a}$ to describe the relaxation behaviour of timothy hay. They indicated the dependencies of the maximal applied stress and the moisture contents of the samples.

Both the relaxation time and the asymptotic modulus characterise the resistance of the crop to the applied deformation.

\subsection{Material preparation}

Due to the flexibility of hay particles, their orientation in a bale is always random. Therefore, the hay samples were only prepared with random oriented particles. Straw samples were prepared in two sets, one with random and another with parallel oriented particles. Each particle orientation had a conditioning method that focuses on maintaining that orientation.

The hay and straw particles for the experiments with random orientation were taken from small square bales, from the summer of 2011. The samples were wetted to have 13, 16, 19, 21, 25 and 30\% w.b. moisture contents. During wetting, the samples were manually mixed to obtain a proper homogeneity and randomization. Afterwards, the samples were put in water-tight bags and were then stored in a cooler at $4^{\circ} \mathrm{C}$ for $48 \mathrm{~h}$ where they were turned every $24 \mathrm{~h}$. Prior to testing, the crop was acclimatised for $12 \mathrm{~h}$ at room temperature.

The parallel oriented particles were unthreshed straw from the harvest season of 2011. Taking into account the ear lengths, the cut height of the combine harvester and the limitations of the compression machine, the straw samples were manually cut to 0.28 $\mathrm{m}$ of length. To avoid ears in the samples, only the bottom $0.28 \mathrm{~m}$ of the wheat straw was used. The samples were then placed in air permeable boxes so that they could be cooled in a forced-air cooler. Saturated wet air was then blown into the boxes at $4^{\circ} \mathrm{C}$ for $48 \mathrm{~h}$. Doing so, the straw reached a moisture content of $30 \%$ w.b.. The indicated lower moisture levels were attained by applying different drying durations with dry air at room temperature.

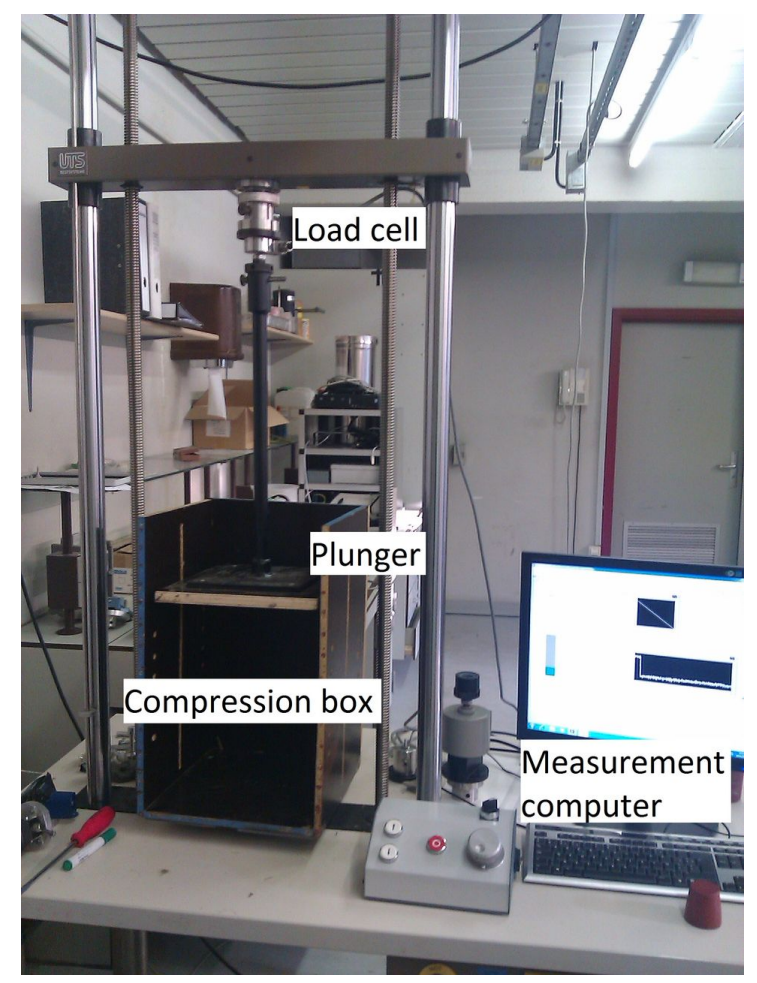

Figure 1: Universal testing machine for measuring the compression profiles. Front wall of the compression box removed for clarity.

The moisture contents of the samples were determined by oven drying at $103^{\circ} \mathrm{C}$ according to the ASABE Standard S358.2 (ASABE Standards, 2006). Three moisture samples per test were taken and the average value was used as the moisture level of the straw.

\subsection{Measurement of the stress-deformation and re- laxation curves}

The compression tests were performed with a universal testing machine (UTS testsysteme $\mathrm{GmbH}$, type $5 \mathrm{~K}$ ) where the compression force was measured with a HBM load cell, type U2A with a maximal force of $5 \mathrm{kN}$ and the deformations were measured with the encoder of the testing machine. The compression speed was set to $16.4 \mathrm{~mm} \mathrm{~s}^{-1}$ for fast and $8.2 \mathrm{~mm} \mathrm{~s}^{-1}$ for slow compression. The compression box had a cross section of 0.30 by $0.30 \mathrm{~m}$ and a depth of $0.50 \mathrm{~m}$. Figure 1 shows the set-up of the compression box and the universal testing machine. In this study, compression profiles were measured until 145 $\mathrm{kg} \mathrm{m}^{-3}$, dry matter. This range covered the expected densities in a commercial baler and enclosed the first 
two phases in the compression.

The UTS test system was also used to measure a stepwise compression with crop relaxation after each step. Every step consisted of a compression of 50 $\mathrm{mm}$ at a $16.4 \mathrm{~mm} \mathrm{~s}^{-1}$ rate, followed by a relaxation at constant deformation during $60 \mathrm{sec}$. This relaxation was modelled using the Maxwell model (Eq. 7) and the model of Peleg (Eq. 8).

The compression profiles at slow and fast velocity and the relaxation curves were each measured with 3 replications per moisture content.

\section{Results and discussion}

First, the process of material compression will be described. Then a quantitative analysis of this process will be given by considering the dependency of the crop parameters with re-compression, moisture content and particle orientation. Finally, the effect of duration of compression will be characterized.

\subsection{The compression process}

In Fig. 2 the force-density relation for multiple compression cycles is shown. For clarity, only one replication is plotted. Variations between replications mainly exist at the higher densities but the change in profile from one cycle to the next is always similar. At the beginning of the first compression cycle, the structure of the bulk will be compressed. The particles thereby move across each other, creating a friction force. As explained by Kaliyan \& Vance Morey (2009), in the first compression phase the weak links will be ruptured and most of the air is pressed out of the bulk. A large part of this deformation is permanent. Once the particles are for the larger part in contact, the compression mainly deforms the particles themselves rather than moving them across each other. During unloading, due to the particle stacking and elasticity, these particles will then push each other back towards their original position. Because the stacking causes the main expansion during unloading, the expansion for subsequent compression cycles is similar. In the second compression cycle, the density of the crop is higher and the compression starts later. The main force in this profile now only has to re-compress the expanded particle structure, causing the compressive forces in the second cycle to be lower than in the first. The force difference between the first and second cycle thus is the force for rupturing weak links, moving particles through each other and pressing out the air. Since this mainly occurs in the first compression phase, the difference will decline with the compression state (density). This decrease also implies that the re-compression curve is steeper than the previous compression curve (Fig. 2, second compression). The third and fourth cycles are more similar to the second. Indeed, the rearrangement of the particles after the second cycle is more a function of time than of the applied deformation and rearrangement of the particles. The effect of time during compression is called creep or relaxation which will be discussed in more detail in Section 3.5.

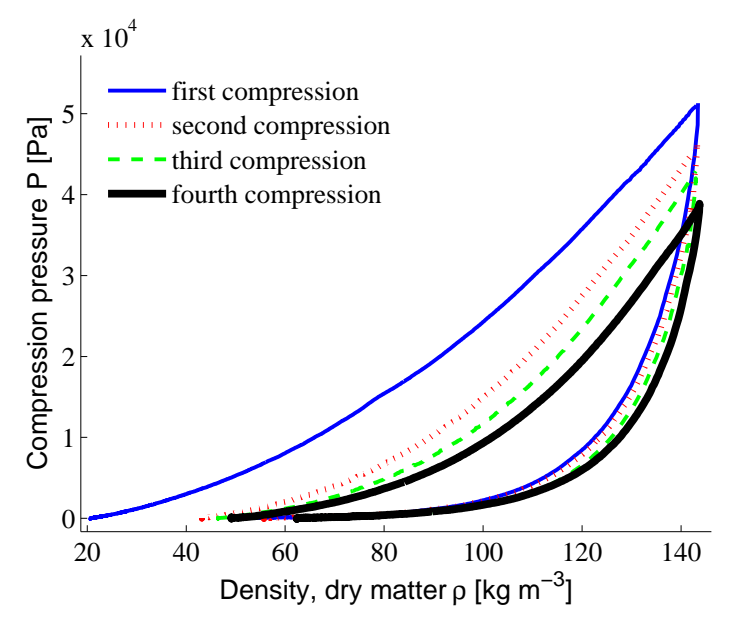

Figure 2: Change of the compression profile with recompression, for hay, $10 \%$ w.b. moisture content

The maximal force in subsequent compression cycles decreases with the number of re-compressions. Kutzbach (1973) describes this with a power-law relation. The curves themselves however, start at higher densities and become more steep in each subsequent compression cycle. As the initial bulk modulus represents the initial phase while the porosity index represents the increase of force at larger deformations, both parameters rise with re-compression. The change of these parameters as a function of recompression and moisture content will be discussed in more detail in the following sections. 


\subsection{Determining parameters from the compression curve}

The crop parameters are determined by fitting the Faborode crop model (Eq. 5) to the force-density data. The two resulting crop properties $\left(K_{0}\right.$ and $\left.b_{c}\right)$ are used to describe the crop behaviour quantitatively. An example fit is shown in Fig. 3. The model gives satisfactory fitting performance. In fact, the $R^{2}$ was never less than 0.8 .

The comparison between the Maxwell (Eq. 4) and Faborode model is only valid for small deformations. Because the performance of both models are to be compared and the assumption of small deformations has to be evaluated, also a least squares fit of the Maxwell model has been fitted (Fig. 3). The resulting $R^{2}$ was similar to that for the Faborode model indicating its similarity. However, this model underestimated both the initial slope and the maximal force so that the Faborode model is preferred. The applicability of the Maxwell model to larger deformations is thus limited. Indeed, the Maxwell model assumed the engineering strain which is only a measure for infinitesimal deformations. By having a closer look at Eq. 6, the strain can be re-defined as: $\epsilon=\left(L-L_{0}\right) \cdot L^{-1}$. This allows for the Maxwell and Faborode model to coincide for all deformations. Redefining the deformation therefore expands the applicability of the Maxwell model to large deformations. In the further analysis, the Faborode model parameters are interpreted but after re-defining the strain, these parameters can be changed to the parameters of the Maxwell model, as indicated in Section 2.1.

\subsection{The initial bulk modulus $K_{0}$}

Care must be taken in comparing the crop parameters of the random and parallel oriented particles. The straw particles with a random orientation were already compressed in small square bales. The first compression cycle thus measures the compression of the stacking rather than the compression of particles. The parallel oriented particles, on the other hand, were unthreshed. The first compression cycle therefore characterises the compression of the particles. After the first compression cycle, the random and parallel oriented particles had a similar compression which was larger than the compression in

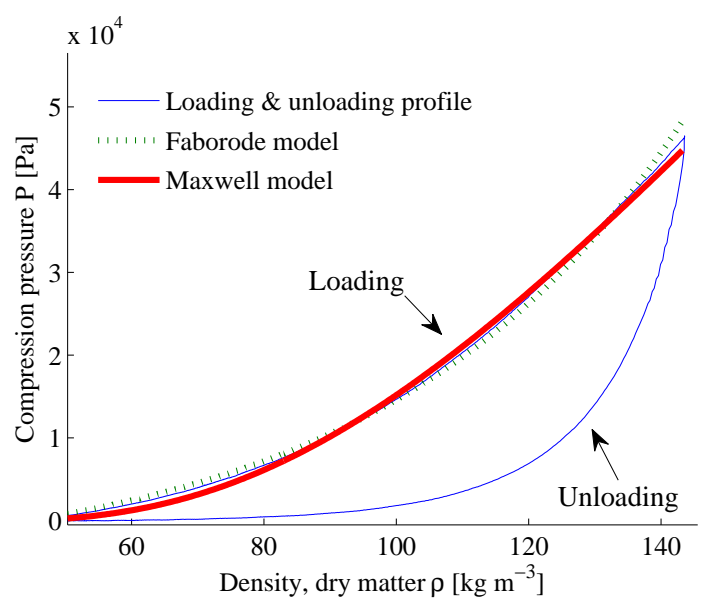

Figure 3: Compression profile for hay at $18 \%$ w.b. moisture content and $16.4 \mathrm{~mm} \mathrm{~s}^{-1}$ compression speed with a fit of the Faborode $\left(R^{2}=0.999\right)$ and Maxwell $\left(R^{2}=0.998\right)$ models. Fit parameters are: $K_{0}=5.950 \mathrm{kPa}, b_{c}=1.0017$ and $E=1.491$ $\mathrm{kPa}, R \eta=187.2 \mathrm{~Pa}$

a small square baler. The resulting particle damage was therefore similar after the first cycle, which makes the compression profiles more comparable.

The initial bulk modulus $K_{0}$ describes the first phase in the compression. Figure 4 shows the change of $K_{0}$ with both re-compression and moisture content. In a certain compression cycle, a significant $(P<0.05)$ change of $K_{0}$ with moisture content is indicated by plotting the trend line.

With the analysis in Section 3.1, the initial bulk modulus will increase with re-compression. This is shown in Fig. 4(a) and (b) where $K_{0}$ increases from the first to the second cycle and then remains approximately constant. Straw with a parallel orientation does not have particles moving across each other. Hence, the permanent deformations and the increase of inter-particle contact after the first cycle are limited. Due to breakage of particles (first compression phase), the effort of re-compression with the subsequent cycles is reduced. Hence, $K_{0}$ of paralleloriented straw decreases with re-compression as shown in Fig. 4(c) and this decrease is larger for drier material. Indeed, a higher moisture content changes the brittleness of the particles, i.e. it prevents them from breaking. Since the random-oriented particles were already compressed in a small square baler, their stacking is more important than the change in brittleness of the particles, causing $K_{0}$ of random- 
oriented straw to increase with re-compression.

It was expected that an increase in moisture content would lubricate the inter-particle movement and would lower $K_{0}$ in the first cycle. However, this effect is only visible for hay. Faborode (1989) measured compression profiles of small straw particles (die size $53 \mathrm{~mm}$ ). He indicated a decrease of $K_{0}$ with moisture content but stated that adding too much water increases the compression resistance because the water takes up space for compression. Hence, at large inter-particle contact an increase in moisture content will increase $K_{0}$. This is shown for random and parallel straw from the second cycle onwards (Fig. 4(b) and (c)).

The elasto-visco-plastic behaviour of straw and hay makes the compression curve dependent on the rate of loading. However, when looking at the alternative model formulation (Eq. 4), $K_{0}$ is independent. The difference of $K_{0}$ at the applied loading rates was tested at significance level $5 \%$. The P-value for random straw was 0.344 , for hay 0.213 and for parallel straw 0.888 , indicating that values of $K_{0}$ at $8.2 \mathrm{~mm}$ $\mathrm{s}^{-1}$ and $16.4 \mathrm{~mm} \mathrm{~s}^{-1}$ are not significantly different for the tested crops.

\subsection{The porosity index $b_{c}$}

The porosity index $b_{c}$ determines the increase of the slope of the compression curve near the final density. The change of $b_{c}$ with both re-compression and moisture content is shown in Figure 5. In a certain compression cycle, a significant $(P<0.05)$ change of $b_{c}$ with moisture content is indicated by plotting the trend line.

At larger inter-particle contact, the compression curve will be steeper and $b_{c}$ will be higher. Therefore, $b_{c}$ will rise with subsequent re-compressions as can be seen in Fig. 5. Since a higher moisture content also increases the inter-particle contact, $b_{c}$ also increases (Fig. 5(a) for hay). However, an increase in moisture content also softens the particles and the effect is mainly visible for more brittle straw particles, especially the parallel oriented ones which were unthreshed. In the case of random-oriented straw, the particles themselves were already compressed. Therefore, the softening of the particles is not significant for random-oriented straw particles, as can be seen in Fig. 5(b). In the first cycle however, the

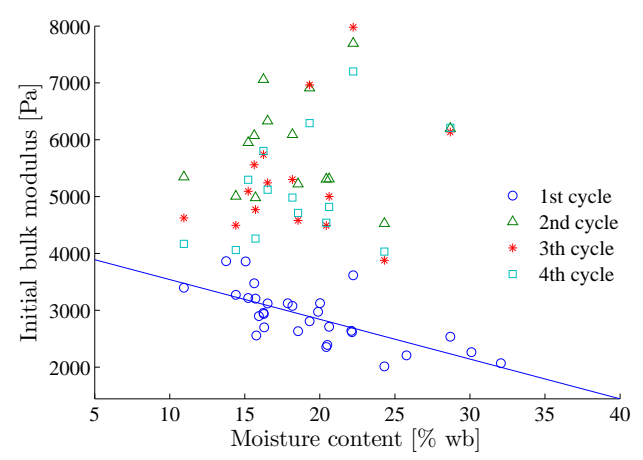

(a) Hay

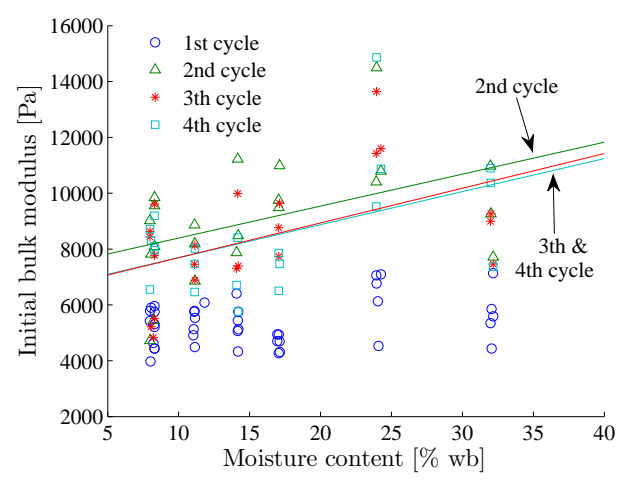

(b) Straw, random orientation

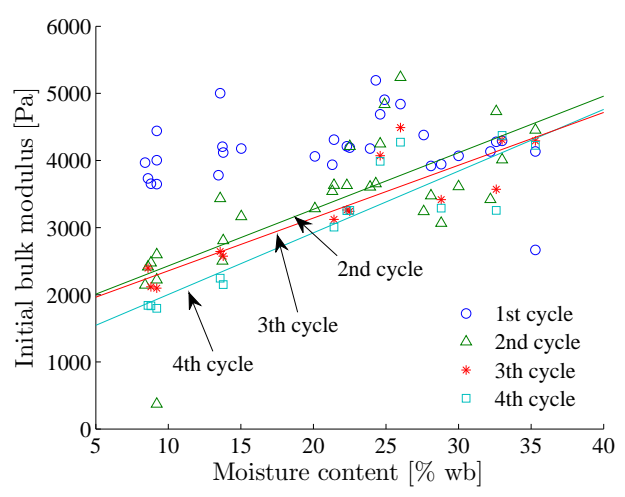

(c) Straw, parallel orientation

Figure 4: The change of $K_{0}$ with moisture content and recompression

increase in moisture content lowers the friction force for moving the particles across each other. Faborode (1989) described an increase of $b_{c}$ with moisture content but considered only small particles (die size of $53 \mathrm{~mm}$ ). Therefore, the effect of moisture was mainly limited by increasing the inter-particle contact and hence increasing $b_{c}$.

Since $b_{c}$ is given by the ratio of the elastic modulus and the viscosity coefficient of the Maxwell model (Section 2.1), an increase in $b_{c}$ means an increase in the elastic behaviour with respect to the viscous be- 


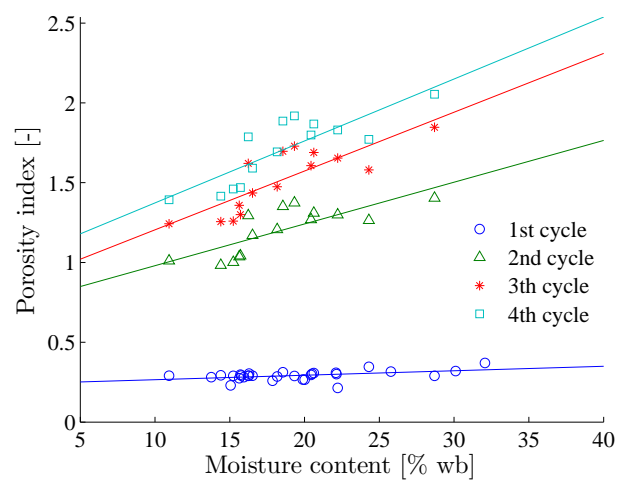

(a) Hay

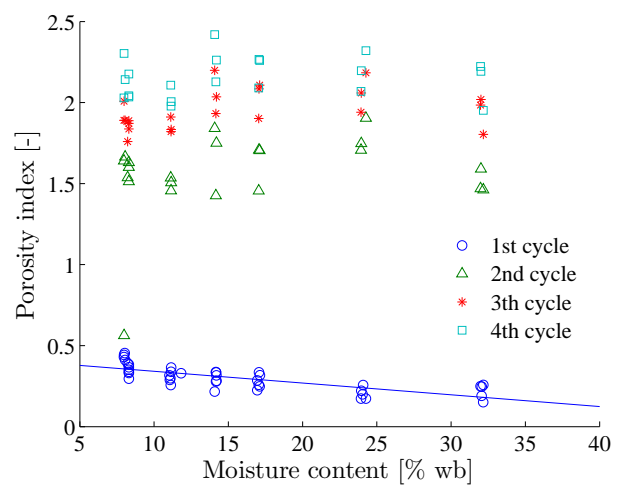

(b) Straw, random orientation

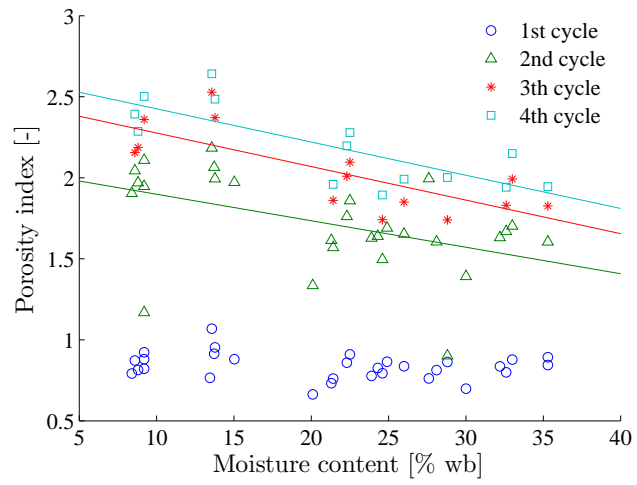

(c) Straw, parallel orientation

Figure 5: The change of $b_{c}$ with moisture content and recompression

haviour of the material. Therefore, re-compression makes the crop act more elastic and by adding moisture either the crop becomes more viscous or the particles become more elastic.

Pressing out the air between particles is similar to the compression of a damper. The viscosity of the air and the tortuosity of air canals between the particles determine the visco-plastic compression behaviour. Therefore, the compression is expected to depend on the loading rate. From the similarity between the
Maxwell and Faborode model, it was expected that $b_{c}$ defines this effect. The two-sided $t$-test at $5 \%$ significance level indicated a significant effect of the loading rate on the porosity coefficient $b_{c}$ for parallel straw ( $\mathrm{P}=0.037)$, but no significant effect for random straw $(P=0.366)$ and hay $(P=0.889)$. It is assumed that the large inter-particle contact for parallel oriented straw allowed $b_{c}$ to change with the applied difference in loading rate. For random oriented straw with larger air voids between the particles, the change in applied loading rates was not sufficient in changing the effort of pressing out the air. For proper evaluation of this statement, extra measurements are required at higher compression velocities.

\subsection{Relaxation parameters}

In Fig. 6, a relaxation experiment of the increase in force due to $50 \mathrm{~mm}$ extra compression is shown. At the maximal force, the plunger stops and holds the deformation. Then, the relaxation starts and the models are fitted. The start of the relaxation is put at time $t=0$. Although the $R^{2}$ of the Maxwell model was

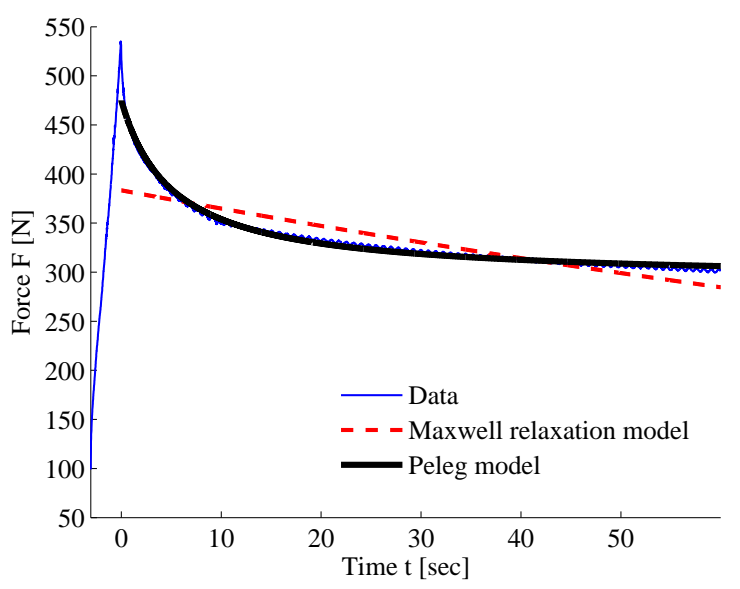

Figure 6: Fit of stress relaxation with Maxwell and Peleg model for hay at $15.8 \%$ w.b. moisture content. The parameters of the Maxwell model are $\sigma_{0}=383 \mathrm{~Pa}$ and $\eta E^{-1}=201 \mathrm{sec}$ and for the Peleg model $k_{1}=2.59 \mathrm{sec}, k_{2}=13.33$ and $F_{0}=475 \mathrm{~N}$

quite high (about 0.7), the Peleg model performed considerably better $\left(R^{2}>0.8\right)$. It should however be noted that the Peleg model was not able to predict the initial, steepest descend of the relaxation curve and hence was found to be accurate only after $1 \mathrm{sec}$ of relaxation (Fig. 6). Since both models were unable to capture the initial steepest descent, both the 
model parameters and the initial stresses had to be estimated by the fit.

Because the Maxwell model does not fit properly and the Peleg model cannot capture the initially relaxation, only the asymptotic modulus of the Peleg model can be used to properly describe the mechanism of relaxation near the end of the relaxation period. The asymptotic modulus $\left(E_{a}\right)$ represents the change of the internal structure with time (Peleg, 1980) and small $E_{a}$ corresponds to small stress decay with time. A larger applied strain increases the required compression force. Therefore, a larger resistance to compression exists and $E_{a}$ increases. This corresponds to the plot of the asymptotic modulus to strain which is shown for hay and randomoriented straw in Fig. 7(a) and (c). For the paralleloriented straw, the particles are already in large contact. Hence, an extra deformation is the deformation of the particles. At the initially small deformations $(<0.4)$, the particles break causing the $E_{a}$ to be high and at small increase of strain to drop rapidly (Fig. 7(b)). For larger compressions (>0.4) the $E_{a}$ acts similar to the $E_{a}$ of random-oriented straw. It should be noted that in the performed tests, the particles of hay and random-oriented straw were already broken because they originate from small square bales. Only for sufficiently high strains, the damage of the parallel- and random-oriented particles becomes comparable, as can be seen in Fig. 7(b) and (c).

\section{Conclusions}

The compression of straw and hay is characterised by different phases. The current high-density balers compress straw and hay to densities of $200 \mathrm{~kg} \mathrm{~m}^{-3}$, wet matter $\left(180 \mathrm{~kg} \mathrm{~m}^{-3}\right.$ dry matter at $\left.10 \% \mathrm{wb}\right)$. The compression to higher densities was therefore not relevant in this study. This results in two phases of the compression behaviour which were modelled.

In the first compression cycle, the crop particles are first pushed across each other causing large permanent deformations. At larger densities, the effect of inter-particle contact is larger than the rearrangement of particles. Subsequent cycles are therefore steeper. During unloading, the stacking and the elasticity of the particles cause the expansion of the crop. The unloading curves of subsequent cycles are therefore similar.

While the least squares fit of the Maxwell model $\left(R^{2}>0.8\right)$ underestimated both the initial slope of the curve and the final compression stress, the Faborode model was found to describe the compression curves accurately $\left(R^{2}>0.8\right)$. The crop parameters of the Faborode model then properly indicate the change of the compression curve with moisture content and re-compression. The effect on the crop parameters could also be explained by changes in the physical interactions in the first two phases of the compression. Therefore, these parameters also depend on the particle orientation and crop variety. It is shown that, for small deformations, the Maxwell model performs similarly to the Faborode model. Since the Maxwell model separates the elastic and viscous deformation, this similarity allows for separating the elastic and viscous properties of the Faborode model. However, the indicated rate dependency of viscous properties was only significant for parallel-oriented straw $(\mathrm{P}=0.037)$ and not for the random-oriented particles $(\mathrm{P}=0.366)$ and hay $(\mathrm{P}=0.889)$. For further evaluation of the loading rate, extra measurements at higher compression speeds are required.

Two models for the relaxation of straw and hay have been compared. While the model of Maxwell did not give satisfactory results, the Peleg model performed well $\left(R^{2}>0.8\right)$, but only after a relaxation time of $1 \mathrm{sec}$. The model parameters can thus be used to capture the relaxation properties near the end of the relaxation period. 


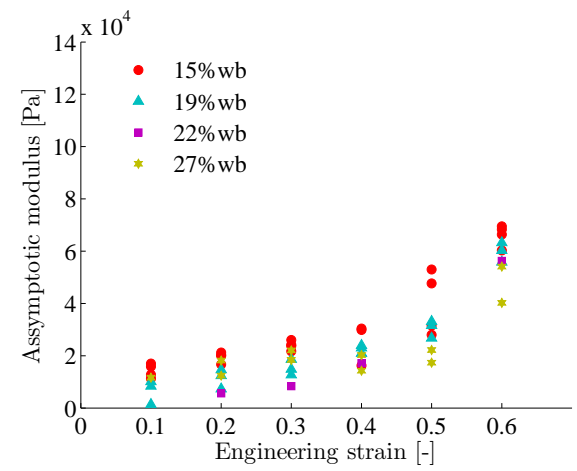

(a) Hay

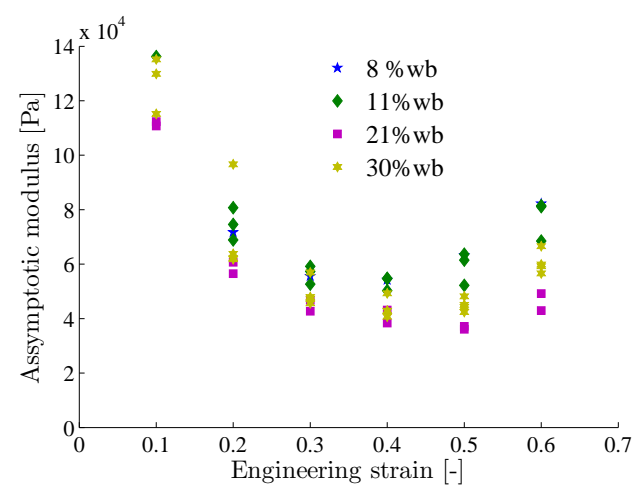

(b) Straw, parallel orientation

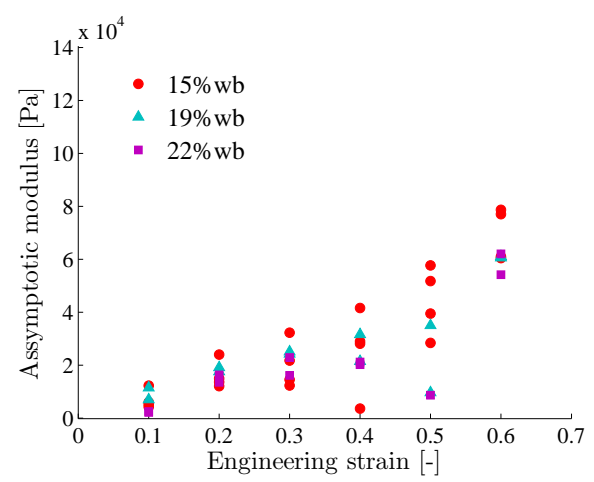

(c) Straw, random orientation

Figure 7: Asymptotic modulus with respect to the engineering strain and moisture content 


\section{References}

Adapa, P., Tabil, L., \& Schounau, G. (2009). Compression characteristics of selected ground agricultural biomass. Agricultural Engineering International: the CIGR Ejournal. Manuscript 1347, XI, 1-19.

Annoussamy, M., Richard, G., Recous, S., \& Guérif, J. (2000). Change in mechanical properties of wheat straw due to decomposition and moisture. Applied Engineering in Agriculture, 16, 657-664.

ASABE Standards (2006). S358.2: Moisture measurement forages. American Society of Agricultural and Biological Engineers (ASABE), St. Joseph, MI.

Chen, B., Cheng, A.-D., \& Chou, T.-W. (2001). A nonlinear compaction model for fibrous preforms. Composites: Part A, 32, 701-707.

Faborode, M. (1986). The compression and relaxation behaviour of fibrous agricultural materials. Ph.D. thesis University of Newcastle upon Tyne.

Faborode, M. (1989). Moisture effects in the compaction of fibrous agricultural residues. Biological Wastes, 28, 61-71.

Faborode, M., \& O' Callaghan, J. (1986). Theoretical analysis of the compression of fibrous agricultural materials. Journal of Agricultural Engineering Research, 35, 175-191.

Faborode, M., \& O' Callaghan, J. (1989). A rheological model for the compaction of fibrous agricultural materials. Journal of Agricultural Engineering Research, 42, 165 - 178.

Faborode, M. O., \& O' Callaghan, J. R. (1987). Optimizing the compression/briquetting of fibrous agricultural materials. Journal of agricultural engineering research, 38, 245262.

Galedar, M. N., Jafari, A., Mohtasebi, S., Tabatabaeefar, A., Sharifi, A., O’Dogherty, M., Rafiee, S., \& Richard, G. (2008). Effects of moisture content and level in the crop on the engineering properties of alfalfa stems. Biosystems Engineering, 101, $199-208$.

Kaliyan, N., \& Vance Morey, R. (2009). Constitutive model for densification of corn stover and switchgrass. Biosystems Engineering, 104, 47-63.

Kutzbach, H. D. (1973). Die grundlagen der halmgutverdichtung. Grundlagen der Landtechnik, 23, 23-24.

Landbouwcentrum Granen Vlaanderen (2009). Granen Oogst 2009. [Brochure] Provinciaal centrum voor land- en tuinbouw, Roeselare, Belgium.

Mohsenin, N. N. (1986). Physical properties of plant and animal materials. Department of Agricultural Engineering, Pennsylvania State.

O'Dogherty, M., \& Gilbertson, H. (1988). The relationship between bulk density and median chop length of chopped wheat straw samples. Journal of Agricultural Engineering Research, 40, 245 - 257.

O’Dogherty, M., \& Wheeler, J. (1984). Compression of straw to high densities in closed cylindrical dies. Journal of Agricultural Engineering Research, 29, 61 - 72.

Osobov, V. (1967). Theoretical principles of compressing fibrous plant materials. Trudy Viskhom, Moscow, 55, 221265.
O' Dogherty, M. J. (1989). A review of the mechanical behaviour of straw when compressed to high densities. Journal of Agricultural Engineering Research, 44, 241 - 265.

Peleg, M. (1980). Linearization of relaxation and creep curves of solid biological materials. Journal of Rheology, 24, 451463.

Rehkugler, G. E., \& Buchele, W. F. (1969). Biomechanics of forage wafering. American Society of Agricultural Engineers, $12,1-8$.

Sitkei, G. (1986). Mechanics of agricultural materials. Elsevier, Amsterdam.

Talebi, S., Tabil, A., Opoku, A., \& Shaw, M. (2011). Compression and relaxation properties of timothy hay. International journal of Agricultural $\mathcal{F}$ Biological Engineering, 4, 69-78.

Viswanathan, R., \& Gothandapani, L. (1999). Pressure density relationships and stress relaxation characteristics of coir pith. Journal of Agricultural Engineering Research, 73, 217 -225 . 